\title{
POTENSI DAN PENGEMBANGAN DESA WISATA SURANADI DI KECAMATAN NARMADA KABUPATEN LOMBOK BARAT
}

\author{
Ni Putu Rika Sukmadewi \\ Universitas Udayana \\ Email: rika.sukmadewi@gmail.com \\ I Nyoman Darma Putra \\ Universitas Udayana \\ Email: idarmaputra@yahoo.com \\ I Wayan Suardana \\ Universitas Udayana \\ Email: suar.dana@gmail.com
}

\begin{abstract}
Indonesia has many areas with the various tourism potentials but faces obstacles in the management, one of them is Suranadi Tourism Village in Narmada District, West Lombok Regency. This research aimed to analyze 1) the potential and tourism management system in Suranadi Tourism Village; 2) internal and external factors affecting the development of Suranadi Tourism Village; 3) the development strategy of Suranadi Tourism Village. This research applies some theories such as tourism destination development theory by Cooper (1993), irridex theory by Doxey (1976), and tripartite attraction design theory by Gunn (1972). This research used qualitative approach with descriptive method. Data obtained through interviews and observation. The method of data analysis in this research is by qualitative data analysis and SWOT analysis. The results showed that the potential of Suranadi Village as a cultural tourism village that is the potential of nature and culture. The various of potentials in the Suranadi Tourism Village as a whole has not managed professionally and optimally so that economic benefits are not fully felt for local community. The results of SWOT matrix analysis showed that there are four alternative strategies generated such as SO strategy (Strengths-Opportunities), ST strategy (Strengths-Threats), WO strategy (Weaknesses-Opportunities), WT strategy (Weaknesses-Threats).
\end{abstract}

Keywords: tourism potential, development strategy, Suranadi Tourism Village, SWOT 


\section{Pendahuluan}

Kegiatan pariwisata memberikan stimulus ekonomi pada perekonomian nasional. Makin banyak pergerakan wisatawan, baik wisman, wisnus, maupun wisnas ke atau di Indonesia, berarti makin besar dan dinamis dampaknya pada pergerakan dan pertumbuhan ekonomi negara. Setiap orang yang bepergian pasti membelanjakan sejumlah uang seperti untuk biaya perjalanan (membeli tiket pesawat terbang), akomodasi, makanan, rekreasi, sampai dengan membeli cinderamata. Makin panjang length of stay (masa tinggal) wisatawan di suatu destinasi berarti makin banyak uang yang dibelanjakan. Makin banyak uang yang dibelanjakan, makin banyak barang dan jasa yang bisa dijual oleh masyarakat, makin banyak pajak yang bisa diraup oleh negara (Putra dan Pitana, 2010).

Dalam memenuhi target Presiden RI untuk mencapai 20 juta kunjungan wisatawan mancanegara di tahun 2019, pemerintah telah melakukan beberapa terobosan di antaranya yaitu dengan adanya deregulasi Bebas Visa Kunjungan (BVK) bagi 169 negara. Terobosan lainnya adalah dengan memberikan kemudahan kunjungan bagi kapal wisata (yacht) dan kapal pesiar (cruise) untuk masuk ke Indonesia sehingga ke depan diharapkan mampu membawa lebih banyak lagi wisatawan mancanegara (Kompas Travel, 2016). Salah satu bentuk pengembangan pariwisata yaitu melalui desa wisata karena dapat memberikan manfaat ekonomi bagi masyarakat desa dan memeratakan pembangunan desa (Detik Travel, 2017).

Desa wisata merupakan salah satu bentuk penerapan pembangunan pariwisata berbasis masyarakat dan berkelanjutan. Melalui pengembangan desa wisata diharapkan terjadi pemerataan yang sesuai dengan konsep pembangunan pariwisata yang berkesinambungan. Di samping itu, keberadaan desa wisata menjadikan produk wisata lebih bernilai budaya pedesaan sehingga pengembangan desa wisata bernilai budaya tanpa merusaknya (Dewi, Fandeli, dan Baiquni, 2013).

Kabupaten Lombok Barat merupakan salah satu kabupaten yang ada di Pulau Lombok yang pernah meraih penghargaan sebagai kabupaten STO 
(Sustainable Tourism Observatory) di tahun 2016 oleh Kementerian Pariwisata dan UNWTO (Republika, 2017). Sebagai bentuk komitmen pemerintah daerah Kabupaten Lombok Barat untuk terus mengembangkan pariwisata berkelanjutan di Lombok Barat yaitu dengan mengeluarkan Peraturan Bupati Lombok Barat Nomor 41 Tahun 2016 tentang Kawasan Desa Wisata di Kabupaten Lombok Barat. Ada 12 desa yang ditetapkan sebagai desa wisata di Kabupaten Lombok Barat, salah satunya yaitu Desa Wisata Suranadi. Keunikan yang dimiliki Desa Wisata Suranadi adalah perpaduan antara budaya dan alamnya. Pengunjung yang datang ke Desa Wisata Suranadi tidak hanya sekedar dapat melihat peninggalan bersejarah berupa pura tetapi juga dapat menyaksikan pemandangan yang masih alami dan suasana sejuk seperti sawah, kebun, hutan dan sungai dengan airnya yang sangat jernih. Desa Wisata Suranadi juga cukup dikenal di kalangan wisatawan nusantara dengan produk olahan kulinernya yaitu berupa dodol buah (nangka, sirsak, durian, dan pisang). Dodol buah tersebut diproduksi secara industri rumahan (home industry) oleh sebagian masyarakat Suranadi. Dari berbagai potensi yang dimiliki seharusnya dapat dikembangkan secara optimal. Namun, para perangkat desa dan masyarakat Desa Suranadi belum sepenuhnya mengerti terkait konsep desa wisata sehingga belum ada tindaklanjut dalam mengembangkan desanya. Selain itu, fasilitas pendukung yang tersedia juga belum memadai dan kunjungan wisatawan masih didominasi wisatawan nusantara. Oleh karena itu, diperlukan analisis mengenai potensi dan strategi pengembangan Desa Wisata Suranadi.

\section{Landasan Teori dan Konsep}

Dalam penelitian ini digunakan tiga teori yaitu teori pengembangan destinasi pariwisata oleh Cooper (1993), teori irridex oleh Doxey (1976), teori tripartite attraction design oleh Gunn (1972). Teori pengembangan destinasi pariwisata oleh Cooper (1993) terdiri dari empat unsur yaitu Attraction, Amenities, Access, Ancillary services yang disingkat dengan formulasi 4A. Teori ini digunakan untuk 
mengidentifikasi dan mengobservasi kawasan Desa Wisata Suranadi dalam mengembangkan pariwisata khususnya untuk mengetahui potensi apa saja yang dimiliki sehingga dalam pengembangan maupun pengelolaannya akan lebih terarah.

Teori irritation index (irridex) ini diperkenalkan oleh Doxey di tahun 1976 untuk mengetahui sikap masyarakat lokal dalam menanggapi kegiatan pariwisata termasuk wisatawan yang berada di daerahnya. Teori Irridex dari Doxey ini menggambarkan perubahan sikap masyarakat lokal terhadap wisatawan secara linier. Terdapat empat fase dari sikap masyarakat lokal tersebut yaitu Euphoria, Aphaty, Annoyance, dan Antagonism (Pitana dan Diarta, 2009).

Teori tripartite attraction design adalah konsep pengembangan dan perencanaan suatu atraksi wisata dengan membaginya menjadi 3 unsur yaitu zona inti (nucleus), zona penyangga (inviolate belt), dan zona pemanfaatan (zone of closure) (Gunn, 1972). Teori ini dipergunakan untuk menentukan kawasan mana saja yang dapat dibangun fasilitas penunjang pariwisata seperti restoran, rumah makan atau akomodasi berupa homestay, villa, dan hotel. Hal ini juga akan memberikan gambaran sejauh mana lahan yang harus dikonservasi sehingga dapat menciptakan pembangunan pariwisata yang berkelanjutan (sustainable tourism development).

Metode analisis data yang digunakan yaitu teknik analisis data kualitatif dan analisis SWOT. Teknik analisis data kualitatif dilakukan dengan mengumpulkan data yang diperoleh dari berbagai sumber yang didukung dengan instrumen penelitian kemudian dilanjutkan dengan pengolahan data lalu dijabarkan secara deskriptif berdasarkan pada rumusan permasalahan dan data yang didapat di lapangan melalui wawancara sedangkan untuk menganalisis strategi pengembangan Desa Wisata Suranadi yaitu dengan menggunakan analisis SWOT dan pendekatan tipologi desa.

Teknik pengumpulan data diperoleh melalui observasi dan wawancara dengan pemilihan narasumber secara purposive sampling dan accidental sampling. 
Purposive sampling diberlakukan kepada stakeholders pariwisata yaitu pemerintah, industri, masyarakat, akademisi, dan media. Accidental sampling merupakan pengambilan sampel yang diambil dari wisatawan baik wisatawan domestik maupun mancanegara yang kebetulan ada di Desa Suranadi. Pemerolehan data ini dipergunakan untuk merumuskan strategi pengembangan Desa Wisata Suranadi.

\section{Strategi Pengembangan}

Marpaung (2002) mengungkapkan bahwa strategi merupakan suatu proses penentuan nilai pilihan dan pembuatan keputusan dalam pemanfaatan sumber daya yang menimbulkan suatu komitmen bagi organisasi yang bersangkutan kepada tindakan-tindakan yang mengarah pada masa depan. Sedangkan menurut Puspa (2006) strategi dapat diartikan sebagai rencana umum yang integratif yang dirancang untuk memberdayakan organisasi pariwisata untuk mencapai tujuan melalui pemanfaatan sumber daya dengan tepat walaupun menemukan banyak rintangan dari pihak pesaing. Sama halnya dengan Porter dalam Rangkuti (2002) mendefinisikan strategi sebagai alat yang sangat penting untuk mencapai keunggulan bersaing. Berdasarkan pendapat Suwantoro (1997) pengembangan adalah suatu proses atau cara menjadikan sesuatu menjadi maju, baik, sempurna, dan berguna. Didukung dengan pernyataan Gunn (1994) bahwa dalam pengembangan pariwisata harus melibatkan tiga sektor, yaitu business sector, nonprofit sector dan governmental sector, dan semakin baik pemahaman dan keterlibatan tiga sektor tersebut maka pengembangan pariwisata akan semakin baik.

\section{Desa Wisata}

Menurut Putra dan Pitana (2010) yang dimaksud dengan desa wisata adalah “pengembangan desa menjadi destinasi wisata dengan sistem pengelolaan yang bersifat dari, oleh, dan untuk masyarakat". Selanjutnya, berdasarkan Panduan Desa Wisata, Kementerian Pariwisata dalam RAKORNAS II Pariwisata 2017, desa wisata 
adalah suatu wilayah dengan luas tertentu dan memiliki potensi keunikan daya tarik wisata yang khas dengan komunitas masyarakatnya yang mampu menciptakan perpaduan berbagai daya tarik wisata dan fasilitas pendukungnya untuk menarik kunjungan wisatawan termasuk di dalamnya kampung wisata karena keberadaannya di daerah kota.

Berdasarkan pendapat Zebua (dalam Sanjaya, 2018:92) menyatakan bahwa desa wisata adalah sebuah kawasan pedesaan yang mempunyai karakteristik khusus untuk menjadi daerah tujuan wisata dengan keunikan fisik maupun kehidupan sosial dan budaya masyarakat setempat sebagai daya tariknya.

\section{Pengembangan Pariwisata}

Pengembangan destinasi pariwisata menurut Mill (2000), bahwa pengembangan destinasi pariwisata hendaknya memperhatikan tingkatan budaya, sejarah, dan ekonomi daerah tujuan wisata. Pengembangan merupakan suatu proses atau suatu cara menjadikan sesuatu menjadi maju, baik, sempurna dan berguna. Pengembangan suatu destinasi pariwisata diharapkan tidak hanya dapat memberikan dampak positif terhadap peningkatan ekonomi masyarakat namun tetap memperhatikan karakter destinasi, budaya, dan daerah.

Didukung dengan pernyataan Suardana (2013) bahwa pengembangan destinasi pariwisata memerlukan teknik perencanaan yang baik dan tepat. Teknik pengembangan harus menggabungkan beberapa aspek penunjang kesuksesan pariwisata. Aspek-aspek tersebut adalah aspek aksesibilitas (transportasi dan saluran pemasaran), karakteristik infrastruktur pariwisata, tingkat interaksi sosial, keterkaitan/kompatibilitas dengan sektor lain, daya tahan akan dampak pariwisata, tingkat resistensi komunitas lokal, dan seterusnya.

Pengembangan pariwisata yang ideal akan selalu menunjukkan kepedulian terhadap pelestarian lingkungan, melibatkan pemerintah dan masyarakat lokal. Pengembangan pariwisata yang melibatkan masyarakat sangat penting untuk 
membuka lapangan kerja, memberikan pemahaman tentang pariwisata, dan meningkatkan kondisi perekonomian masyarakatnya (Demolingo, 2015: 69).

\section{Pembangunan Pariwisata Berbasis Masyarakat}

Putra (2015) berpendapat bahwa ada banyak definisi CBT namun isinya pada dasarnya sama yakni sama-sama menekankan unsur penting partisipasi dan keterlibatan komunitas dalam perencanaan, pengelolaan potensi wisata di wilayahnya. Penekanan juga diberikan pada aspek manfaat ekonomi parwisata yang dikelola agar dinikmati secara luas oleh komunitas pendukung. Terjemahan dari kutipan di atas kurang lebih demikian: Pariwisata berbasis masyarakat adalah bentuk kepariwisataan yang komunitas lokalnya memiliki kontrol dalam keterlibatan pada pembangunan dan pengelolannya secara substansial; dan proporsi manfaat sebagian besar tetap berada di tangan komunitas.

Secara prinsip, menurut Sunaryo (2013), Community Based Tourism (CBT) berkaitan erat dengan adanya kepastian partisipasi aktif masyarkat setempat dalam pembangunan kepariwisataan yang ada. Oleh karena itu, pada dasarnya terdapat tiga prinsip pokok dalam strategi perencanaan pembangunan kepariwisataan yang berbasis pada masyarakat (CBT) yaitu:

a) Mengikutsertakan anggota masyarakat dalam pengambilan keputusan

b) Adanya kepastian masyarkat lokal menerima manfaat dari kegiatan kepariwisataan

c) Pendidikan kepariwisataan bagi masyarakat lokal.

Menurut Natori (dalam Madiun 2008), benefit atau keuntungan yang dapat diantisipasi melalui pembangunan pariwisata berbasis masyarakat yakni:

a) Pembangunan pariwisata berbasis masyarakat membantu mengembangkan rasa ikut bermasyarakat dengan tujuan yang jelas dalam kehidupan bermasyarakat. 
b) Pariwisata sangat bermanfaat untuk pengembangan regional. Berbagai aset alam dan budaya yang dimiliki dapat dimanfaatkan oleh masyarakat untuk memberikan kesempatan kepada wisatawan mempelajari masa lampau tentang aset tersebut.

c) Pembangunan pariwisata berbasis masyarakat mampu mempromosikan kesinambungan alam yang sangat berharga, aset yang memiliki nilai sejarah, lingkungan hidup yang nyaman, serta warna lokal.

\section{Potensi Desa Wisata Suranadi}

Kawasan Desa Wisata Suranadi memiliki banyak potensi berupa potensi budaya dan alam yang dapat dijadikan sebagai atraksi atau daya tarik wisata. Beberapa potensi tersebut ada yang sudah berkembang dan menjadi daya tarik wisata andalan di Desa Wisata Suranadi dan terdapat pula potensi yang belum berkembang dan dikelola. Berikut potensi daya tarik wisata Desa Wisata Suranadi berdasarkan pada Teori Pengembangan Destinasi Pariwisata oleh Cooper (1993) yakni 4A (Attractions, Amenities, Access, dan Ancillary Services).

\section{Attractions}

Potensi wisata yang sudah berkembang dan menjadi daya tarik wisata andalan di Desa Wisata Suranadi yaitu Pura Suranadi dan Taman Wisata Alam Suranadi. Pura Suranadi terdiri atas empat jenis pura antara lain Pura Ulon/Gadoh, Pura Majapahit, Pura Pangentas dan Pura Pabersihan. Di bagian dalam setiap pura tersebut terdapat sumber mata air yang dikenal dengan sebutan Panca Tirtha. Di sebelah Pura Pabersihan terdapat dua kolam pemandian alami yang salah satunya disakralkan dan khusus digunakan sebagai tempat melukat bagi umat Hindu sedangkan kolam yang satunya lagi dapat digunakan bagi semua pengunjung. 


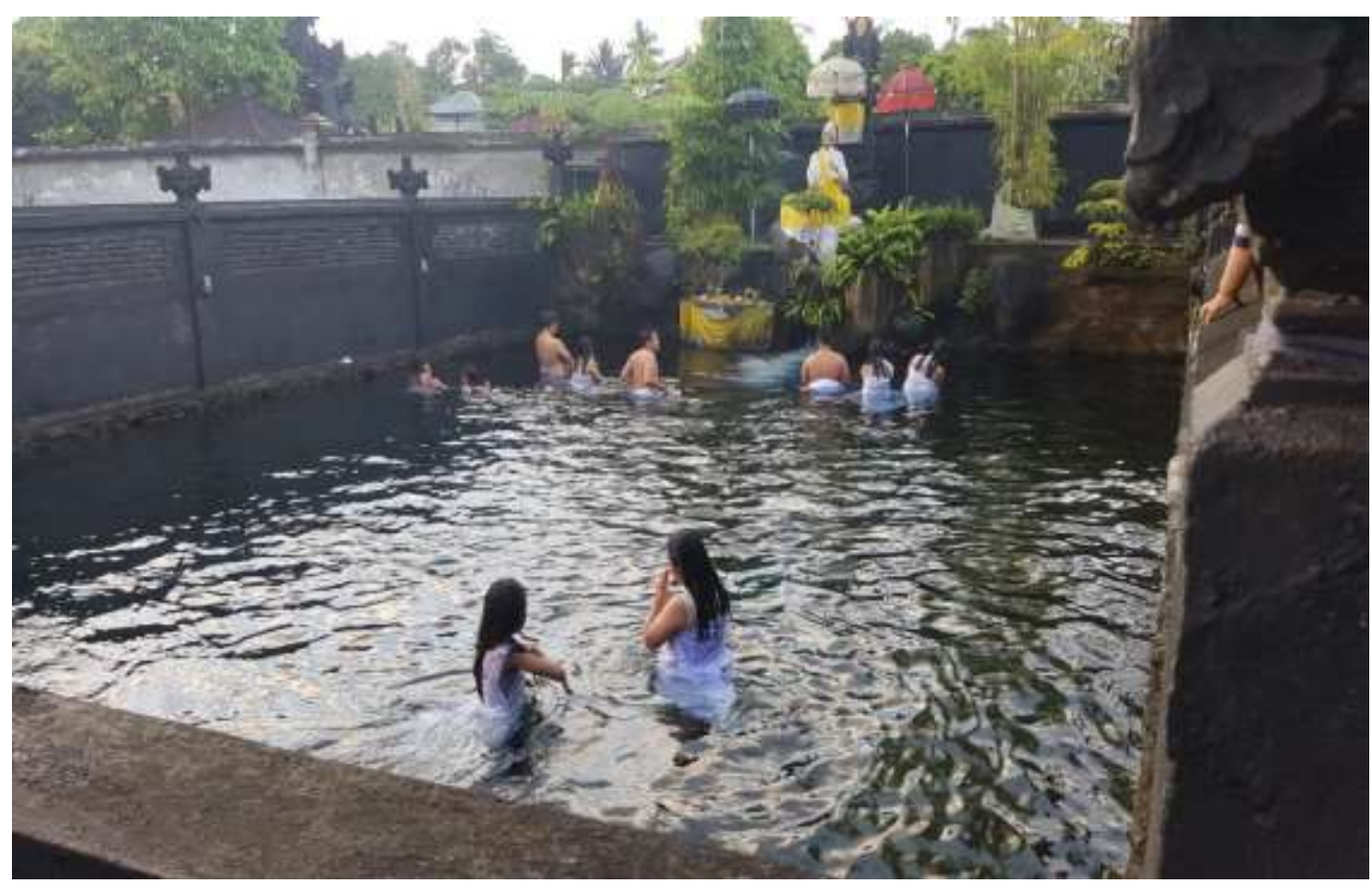

Gambar 1. Kolam Sakral Pura Pabersihan Suranadi Sumber : Dokumentasi Peneliti (2017)

Taman Wisata Alam (TWA) Suranadi merupakan hutan konservasi yang ditetapkan berdasarkan SK Mentan No. 646/Kpts/Um/10/76 tanggal 15 Oktober 1976 dengan luas 52 Ha. TWA Suranadi ini berbatasan langsung dengan Pura Ulon/Gaduh dan Pura Majapahit. Berbagai jenis pepohonan yang menjulang tinggi sekitar 25-30 m, seperti beringin (Ficus sp), garu (Disoxilum sp), terep (Arthocarpus elastica), suren (Toona sureni), kemiri (Aleurites moluccana), purut (Parathocarpus venenoosa), dan pulai (Alstonia scholaris) dapat ditemukan di TWA Suranadi (BKSDA Provinsi NTB, 2015). Selain itu, beberapa jenis satwa juga dapat ditemukan seperti musang dan kera yang berkeliaran bebas bahkan tidak jarang kera-kera tersebut bisa dijumpai di dalam areal Pura Ulon dan Pura Majapahit. Pengelola TWA Suranadi yakni BKSDA (Balai Konservasi Sumber Daya Alam Provinsi NTB memanfaatkan potensi di Taman Wisata Alam Suranadi dengan atraksi buatan yaitu berupa camping area dan outbound yang hanya disediakan bila ada permintaan dari 
wisatawan. Selain itu, terdapat pula jogging track bagi wisatawan yang ingin mengelilingi area hutan.

Selain Pura Suranadi dan TWA Suranadi, ada juga potensi lainnya namun belum dikembangkan dan dikelola seperti pertanian dan perkebunan, suasana pedesaan yang masih asri dan sejuk, sungai, keanekaragaman budaya, ritual upacara adat/keagamaan dan kesenian Genggong.

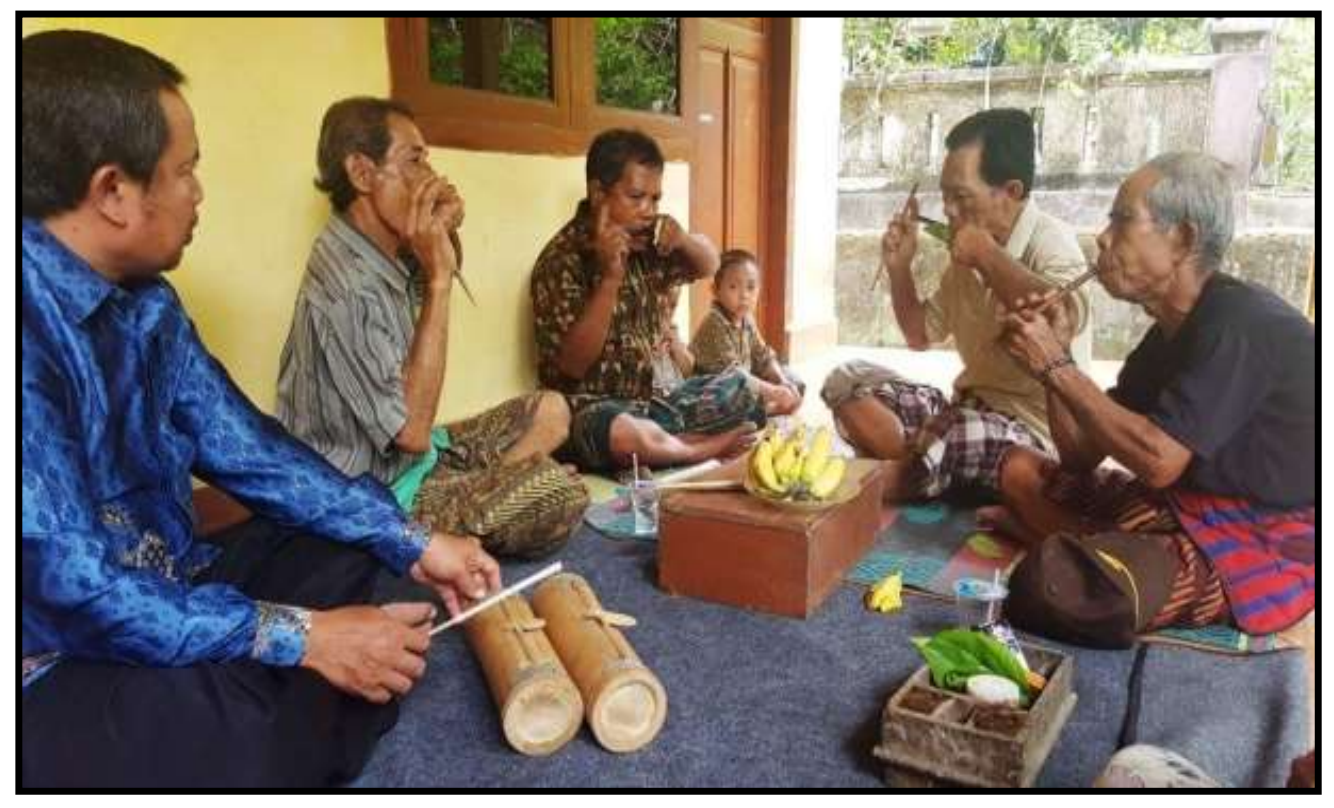

Gambar 2. Masyarakat Lokal memainkan alat kesenian Genggong Sumber : Dokumentasi peneliti (2017)

Potensi-potensi yang terdapat di Desa Suranadi sangatlah beragam, namun pemerintah dan masyarakat belum dapat memanfaatkan dengan baik. Maka dari itu diperlukan inovasi dan kreatifitas dari masyarakat Suranadi untuk mengembangkan berbagai potensi wisata yang ada sehingga dapat mendatangkan banyak wisatawan sehingga memberikan dampak terhadap perekonomian masyarakat lokal.

\section{$\underline{\text { Amenities }}$}

Usaha jasa penginapan (Hotel/Homestay/Villa) sudah tersedia di Desa Wisata Suranadi sebanyak 21 usaha yang sudah terdata tetapi masih banyak juga yang belum memiliki izin usaha. Para pengusaha jasa penginapan/homestay berasal dari 
masyarakat lokal dan beberapa berasal dari luar Desa Suranadi. Fasilitas penunjang lainnya seperti pasar kuliner yang menyajikan makanan khas Lombok berupa sate bulayak, pelecing, pecel, beberuq, dll. serta produk olahan khas Suranadi seperti dodol buah (nangka, sirsak, pisang) juga dapat ditemukan di Suranadi.

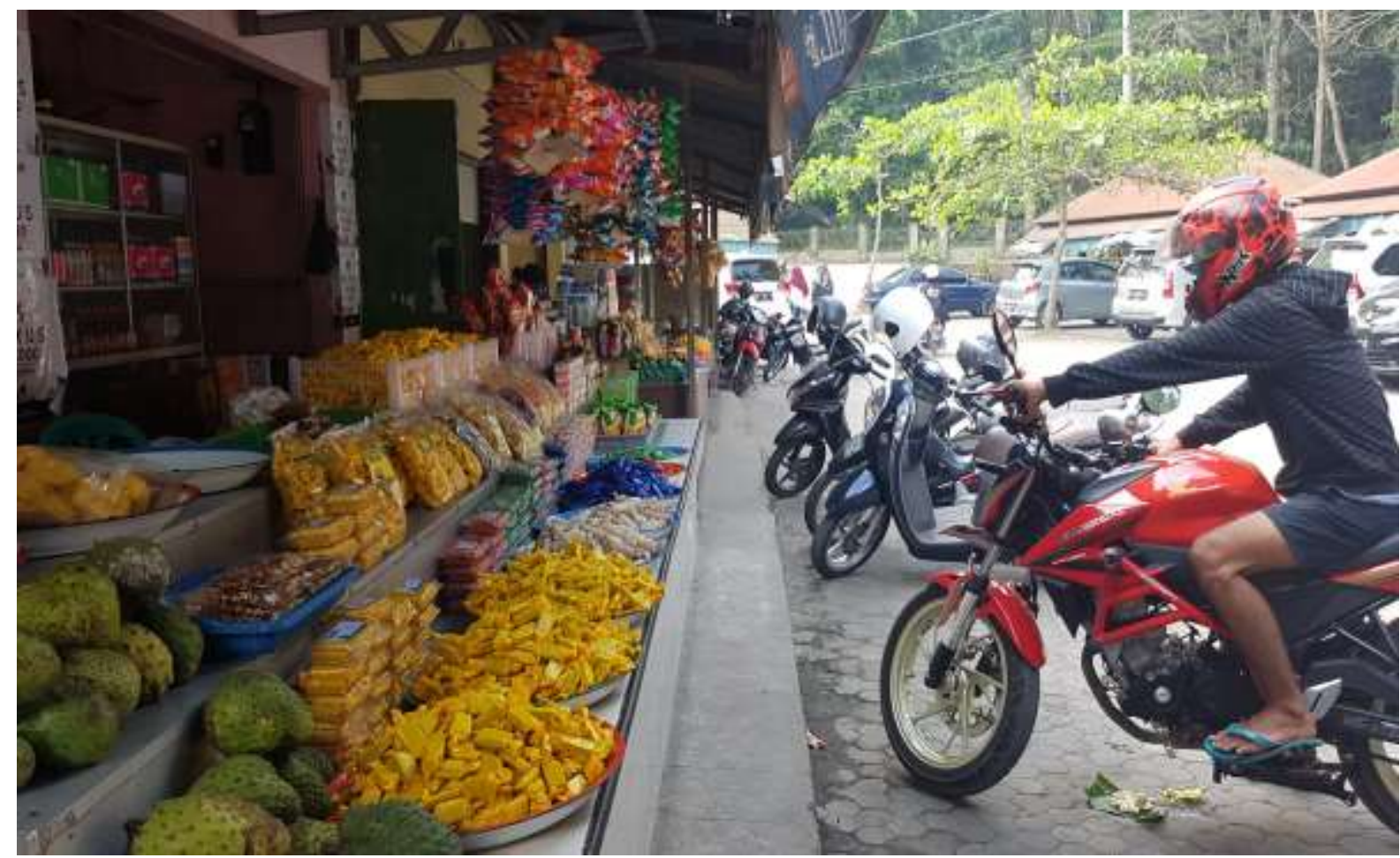

Gambar 3. Pasar Kuliner Desa Wisata Suranadi

Sumber : Dokumentasi Peneliti (2017)

\section{$\underline{\text { Access }}$}

Desa Wisata Suranadi memiliki infrastruktur jalan yang memadai dan dapat diakses dengan berbagai macam kendaraan seperti, bus, mobil ataupun sepeda motor. Jarak Desa Wisata Suranadi dari pusat Kota Mataram hanya $17 \mathrm{~km}$ dengan waktu tempuh sekitar 30 menit perjalanan. Sepanjang perjalanan dari kota Mataram menuju Desa Wisata Suranadi relatif aman dan mudah untuk dilalui karena kondisi medannya yang tidak terjal serta kondisi lalu lintas masih terbilang lancar karena jarang adanya kemacetan kecuali disaat ada pelaksanaan upacara adat. 


\section{$\underline{\text { Ancillary Services }}$}

Organisasi di Desa Suranadi yang telah dibentuk oleh pemerintah daerah Kabupaten Lombok Barat adalah Kelompok Sadar Wisata (POKDARWIS) dengan beranggotakan masyarakat lokal yang berjumlah 9 orang. Organisasi ini sudah dibentuk sejak tahun 2011. Namun, sampai saat ini belum terlihat program kerja nyatanya dalam pengembangan Desa Suranadi sebagai Desa Wisata. Berdasarkan hasil pengamatan, promosi daya tarik wisata di Desa Suranadi sangat kurang, baik melalui media cetak, elektronik atau media sosial, sehingga banyak potensi-potensi wisata yang dimiliki belum dikenal oleh masyarakat luas. Oleh karena itu, pelatihan dan pembinaan terhadap organisasi POKDARWIS tersebut sangat diperlukan agar dalam memasarkan maupun mensosialisasikan Sapta Pesona dapat berjalan sesuai dengan harapan.

\section{Sikap Masyarakat Lokal Desa Wisata Suranadi terhadap Pariwisata}

Berdasarkan analisis dari hasil wawancara kepada masyarakat Desa Wisata Suranadi dan wisatawan, sikap masyarakat lokal terhadap kehadiran pariwisata di Desa Wisata Suranadi berdasarkan pada Teori Irritation Index oleh Doxey (1976) secara umum berada pada fase Euphoria. Pada tahapan ini masyarakat Desa Suranadi memandang pariwisata sebagai sektor yang memberikan peluang terhadap pertumbuhan ekonomi di desa nya. Dengan adanya kehadiran wisatawan di Desa Suranadi, masyarakat lokal mengharapkan manfaat ekonomi yang dihasilkan bisa memberikan lapangan pekerjaan baru dan produk wisata yang dimiliki memiliki nilai ekonomi sehingga pendapatan masyarakat pun juga semakin meningkat. 


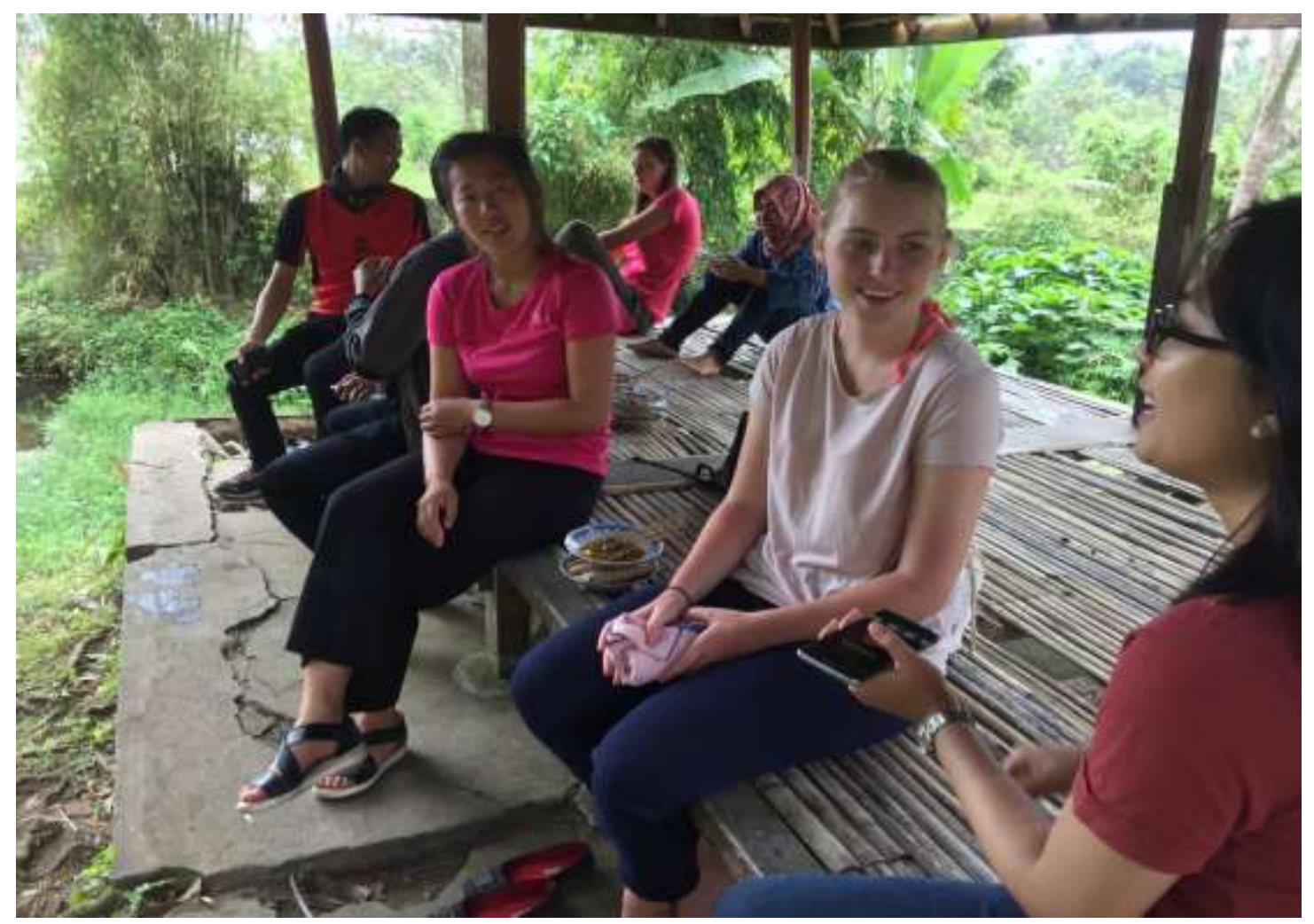

Gambar 4. Wawancara dengan Wisatawan Mancanegara yang berasal dari Belanda Sumber : Dokumentasi Peneliti (2017)

\section{Faktor Internal dan Eksternal Desa Wisata Suranadi}

Sebelum merumuskan strategi pengembangan di Desa Suranadi maka ditentukan terlebih dahulu faktor internal dan eksternal. Faktor internal adalah faktor-faktor yang mempengaruhi pengembangan kawasan Desa Wisata Suranadi yakni Kekuatan (Strenghts) dan Kelemahan (Weaknesses). Penentuan faktor internal didasari atas beberapa variabel yang terdiri dari produk, sumber finansial, sumber daya manusia (SDM), ketersediaan fasilitas, akses, dan promosi. Faktor internal adalah faktor-faktor yang mempengaruhi pengembangan kawasan Desa Wisata Suranadi adalah Peluang (Opportunities) dan Ancaman (Threats). Penentuan faktor eksternal didasari atas beberapa variabel yang terdiri dari sosial budaya, ekonomi, lingkungan, politik, dan teknologi (Evans, Campbell, dan Stonehouse, 2003). Faktor internal dan eksternal dapat dilihat pada Tabel 1. 
Tabel 1. Faktor Internal dan Eksternal Desa Wisata Suranadi

\begin{tabular}{|c|c|c|c|}
\hline \multirow[b]{2}{*}{$\mathrm{NO}$} & \multicolumn{3}{|c|}{ FAKTOR INTERNAL } \\
\hline & \multicolumn{2}{|l|}{ STRENGTHS (S) } & WEAKNESSES (W) \\
\hline S1 & $\begin{array}{l}\text { Kehidupan budaya antara Suku Bali } \\
\text { Hindu dan Sasak Islam yang harmonis }\end{array}$ & W1 & $\begin{array}{l}\text { Kurangnya atraksi wisata seperti } \\
\text { pergelaran kesenian }\end{array}$ \\
\hline S2 & $\begin{array}{l}\text { Adanya Pura Suranadi dan kolam } \\
\text { pelukatan yang berfungsi sebagai tempat } \\
\text { wisata spiritual }\end{array}$ & W2 & $\begin{array}{l}\text { Kurangnya sumber dana untuk } \\
\text { mengembangkan Desa } \\
\text { Suranadi }\end{array}$ \\
\hline S3 & $\begin{array}{l}\text { Kawasan Desa Wisata Suranadi } \\
\text { memiliki panorama alam yang indah, } \\
\text { berhawa sejuk dan masih asri }\end{array}$ & W3 & $\begin{array}{l}\text { Masyarakat lokal yang belum } \\
\text { memiliki keterampilan di bidang } \\
\text { pelayanan pariwisata }\end{array}$ \\
\hline S4 & $\begin{array}{l}\text { Memiliki keunggulan produk pertanian } \\
\text { berupa buah-buahan }\end{array}$ & W4 & $\begin{array}{l}\text { Sarana dan prasarana pariwisata yang } \\
\text { belum memadai }\end{array}$ \\
\hline S5 & $\begin{array}{l}\text { Aksesibilitas yang mudah dijangkau } \\
\text { dari pusat Kota Mataram }\end{array}$ & W5 & $\begin{array}{l}\text { Kurangnya Sosialisasi dan Promosi } \\
\text { Desa Wisata Suranadi }\end{array}$ \\
\hline & \multicolumn{3}{|c|}{ FAKTOR EKSTERNAL } \\
\hline NO & OPPORTUNITIES (O) & & THREATS (T) \\
\hline O1 & $\begin{array}{l}\text { Trend pariwisata yang mengarah pada } \\
\text { sustainable tourism dan CBT salah } \\
\text { satunya yaitu desa wisata dan semakin } \\
\text { padatnya aktivitas di perkotaan } \\
\text { sehingga desa menjadi alternatif wisata }\end{array}$ & $\mathrm{T} 1$ & $\begin{array}{l}\text { Budaya yang dibawa wisatawan dan } \\
\text { arus globalisasi }\end{array}$ \\
\hline $\mathrm{O} 2$ & $\begin{array}{l}\text { Destinasi Indonesia yang murah } \\
\text { sebagai salah satu keunggulan pada } \\
\text { indeks kompetitif pariwisata dunia }\end{array}$ & $\mathrm{T} 2$ & $\begin{array}{l}\text { Komodifikasi budaya lokal untuk } \\
\text { pariwisata }\end{array}$ \\
\hline $\mathrm{O} 3$ & Kondisi yang aman dan kondusif & T3 & $\begin{array}{l}\text { Lingkungan Desa Wisata Suranadi } \\
\text { yang kurang bersih }\end{array}$ \\
\hline $\mathrm{O} 4$ & $\begin{array}{l}\text { Kebijakan Pemerintah yang } \\
\text { mendukung Desa Suranadi ditetapkan } \\
\text { sebagai Desa Wisata }\end{array}$ & $\mathrm{T} 4$ & Kapitalisasi aset lokal oleh orang asing \\
\hline O5 & $\begin{array}{l}\text { Kemajuan Teknologi Informasi dan } \\
\text { transportasi yang berkembang pesat }\end{array}$ & $\mathrm{T} 5$ & $\begin{array}{l}\text { Trend pariwisata digital yang belum } \\
\text { dikuasai } \\
\text { masyarakat Desa Wisata Suranadi }\end{array}$ \\
\hline
\end{tabular}

\section{Strategi Pengembangan Desa Wisata Suranadi}

Berdasarkan hasil identifikasi dari faktor internal dan faktor eksternal maka dihasilkan empat alternatif strategi, yaitu strategi SO (Strenghts-Opportunities), strategi ST (Strenghts-Threats), strategi WO (Weaknesses-Opportunities) dan strategi WT (Weaknesses-Threats) untuk mengembangkan Desa Wisata Suranadi, antara lain: 


\section{Strategi SO}

a) Bekerjasama dengan para stakeholder pariwisata untuk menyusun program Desa Wisata Suranadi yang unggul.

b) Memanfaatkan keunggulan desa untuk menambah daya tarik wisata Desa Wisata Suranadi.

c) Mempromosikan produk lokal buah-buahan dan nuansa Desa Suranadi yang masih asri dengan memanfaatkan teknologi dan harga yang kompetitif.

\section{Strategi ST}

a) Mengemas budaya lokal sebagai daya tarik dengan festival atau pentas seni dan budaya

b) Membina masyarakat lokal dalam menggunakan media sosial dan internet untuk mempromosikan Desa Wisata Suranadi

c) Membuat kegiatan kebersihan bersama serta tim kebersihan

d) Pemberdayaan masyarakat lokal dalam mengembangkan UMKM dan membina masyarakat lokal dalam mengelola sumber daya lokal

\section{Strategi WO}

a) Membenahi infrastruktur dan membangun fasilitas pariwisata secara bertahap sehingga Desa Wisata Suranadi mampu diakses wisatawan dengan baik.

b) Menggiatkan POKDARWIS dalam memasyarakatkan Sapta Pesona serta memberdayakan masyarakat lokal sehingga memberikan rasa aman dan nyaman bagi wisatawan.

c) Pemerintah Desa Suranadi agar memanfaatkan kebijakan desa wisata untuk mengajukan proposal dana dan kegiatan seni budaya sebagai atraksi Desa Wisata Suranadi.

\section{Strategi WT}

a) Melindungi dan mengembangkan budaya lokal dengan membina sanggar dan mengapresiasi seniman lokal. 
b) Mencanangkan program pemberdayaan masyarakat di bidang pariwisata demi terwujudnya Badan Pengelola Desa Wisata Suranadi.

c) Memaksimalkan anggaran yang ada untuk memberdayakan masyarakat dan mengoptimalkan media sosial dalam penyebaran informasi.

\section{Simpulan dan Saran}

Berdasarkan dari hasil analisis dan pembahasan sebelumnya maka dapat ditarik dua simpulan sebagai berikut. Pertama, potensi yang dimiliki Desa Suranadi sebagai desa wisata budaya yaitu potensi alam dan budaya. Dari berbagai potensi yang terdapat di Desa Wisata Suranadi secara keseluruhan belum dikelola secara profesional dan optimal sehingga manfaat ekonomi belum sepenuhnya dirasakan oleh masyarakat lokal. Berdasarkan teori irridex sikap masyarakat Desa Suranadi berada pada fase Euphoria yang berarti masyarakat mengharapkan pariwisata berkembang di desanya karena dipandang mampu memberikan manfaat ekonomi. Kedua, berdasarkan pada uraian dari keempat strategi yang dihasilkan yaitu strategi SO, strategi ST, strategi WO, dan strategi WT menunjukan bahwa kegiatan pengembangan kepariwisataan pada hakekatnya melibatkan peran dari stakeholders pariwisata yang ada dan terkait serta tidak dapat berdiri sendiri, harus saling bersinergi dan melangkah bersama-sama untuk mencapai dan mewujudkan tujuan dan sasaran yang disepakati. Masyarakat memiliki kedudukan dan peran penting dalam mendukung keberhasilan pengembangan Desa Wisata Suranadi. Oleh karena itu, dalam kerangka kegiatan pengembangan kepariwisataan khusunya pengembangan Desa Wisata, maka setiap upaya atau program pembangunan yang dilaksanakan harus memperhatikan posisi, potensi dan peran masyarakat sebagai subyek atau pelaku pengembangan pariwisata demi terwujudnya pariwisata berkelanjutan.

Dalam mengembangkan Desa Wisata Suranadi disarankan pemerintah desa segera mengambil sikap untuk mengembangkan segala potensi baik potensi alam 
maupun budaya yang ada di Desa Wisata Suranadi. Dalam hal ini tentunya diperlukan koordinasi yang baik dengan seluruh komponen desa untuk menyamakan pendapat dan persepsi sehingga terbentuk program desa wisata yang unggul dan kompetitif. Selain itu, komitmen dari pemerintah desa untuk menggandeng pemerintah daerah serta bekerjasama dengan pihak swasta maupun akademisi juga sangat diperlukan terkait dalam pembinaan dan pelatihan SDM agar dapat dibentuk Badan Pengelola Desa Wisata Suranadi. Selain itu, masyarakat lokal perlu berperan aktif dalam penataaan daya tarik wisata dengan membuat spot foto yang unik dan menarik (instragammable) mengingat penggunaan media sosial saat ini sedang booming. Hal ini dilakukan sebagai upaya untuk meningkatkan nilai jual dari daya tarik wisata yang ada di Desa Wisata Suranadi.

\section{Daftar Pustaka}

BKSDA Provinsi NTB. 2015. "Taman Wisata Alam Suranadi, Narmada-Kabupaten Lombok Barat", sumber: https://bksdantb.org/42/04/taman-wisata-alamsuranadi-narmada-kabupaten-lombok-barat/ Diakses 15 Juli 2017.

Cooper, Chris, John Fletcher, David Gilbert, dan Stephen Wanhill. 1993. Tourism: Principles and Practice. London: Longman Group UK Limited.

Demolingo, Ramang Husin. 2015. "Strategi Pengembangan Destinasi Wisata Desa Bongo, Kabupaten Gorontalo", JUMPA, Vol. 1, No. 2, pp. 67-82.

Detik Travel. 2017. “Kembangkan Desa Wisata, Kemendes PDTT Akan Bangun 5.000 Homestay", sumber: https://travel.detik.com/advertorial-news-block-travel/d3507980/kembangkan-desa-wisata-kemendes-pdtt-akan-bangun-5000homestay Diakses 21 Desember 2017.

Dewi, Fandeli, Baiquni. 2013. "Pengembangan Desa Wisata Berbasis Partisipasi Masyarakat Lokal di Desa Wisata Jatiluwih Tabanan, Bali", KAWISTARA, Vol. 3, No. 2, pp. 117-226.

Evans, Nigel, David Campbell, dan George Stonehouse. 2003. Strategic Management for Travel and Tourism. China: Elsevier Ltd.

Gunn, Clare A. 1972. Vacationscape: Designing Tourist Regions. Texas: Bureau of Business Research, The University of Texas at Austin. 
Gunn, Clare A. 1994. Tourism Planning: Basics, Concepts, Cases/Third Edition. United Kingdom: Taylor \& Francis Ltd.

Kompas Travel. 2016. “Tiga Program Prioritas Kemenpar Tahun 2017”, sumber: http://travel.kompas.com/read/2016/12/22/071600127/tiga.program.prioritas.k emenpar.tahun.2017 Diakses 14 Juli 2017.

Madiun, I Nyoman. 2008. Disertasi: "Partisipasi Masyarakat Lokal dalam Pengembangan Kawasan Pariwisata Nusa Dua (Perspektif Kajian Budaya)". Denpasar: UNUD.

Marpaung, Happy. 2002. Pengetahuan Pariwisata. Bandung: Alfabeta.

Mill, Robert Christine. 2000. Tourism The International Bussines. Jakarta: Raja Grafindo Persada.

Peraturan Bupati Lombok Barat Nomor 41 tentang Kawasan Desa Wisata. 2016. Gerung: Pemerintah Daerah Kabupaten Lombok Barat.

Pitana, I Gde dan I Ketut Surya Diarta. 2009. Pengantar Ilmu Pariwisata. Jakarta: Andi.

Putra, I Nyoman Darma. 2015. Pariwisata Berbasis Masyarakat Model Bali. Denpasar: Program Studi Magister Kajian Pariwisata Universitas Udayana bekerjasama dengan Buku Arti.

Putra, I Nyoman Darma dan I Gde Pitana. 2010. Pariwisata Pro-Rakyat Meretas Jalan Mengentaskan Kemiskinan di Indonesia. Jakarta: Kementerian Kebudayaan dan Pariwisata.

Puspa, Ida Ayu Tari. 2006. Tesis: "Potensi dan Strategi Pengembangan Puri sebagai Objek dan Daya Tarik Wisata City Tour di Kota Denpasar". Denpasar: Universitas Udayana.

Rangkuti, Freddy (2002). Measuring Customer Satisfaction: Teknik Mengukur dan Strategi Meningkatkan Kepuasan Pelanggan dan Analisis Kasus PLN-JP. Jakarta: PT. Gramedia Pustaka Utama.

Republika. 2017. “Lombok Barat Garap Pengembangan Pariwisata Berkelanjutan”, sumber:http://www.republika.co.id/berita/gayahidup/travelling/17/10/24/oyb x1b284-lombok-barat-garap-pengembangan-pariwisata-berkelanjutan Diakses 23 Desember 2017.

Sanjaya, Rindo Bagus. 2018. "Strategi Pengembangan Pariwisata Berbasis Masyarakat di Desa Kemetul, Kabupaten Semarang", JUMPA, Vol. 5, No. 1, pp. 91-110.

Suardana, I Wayan. 2013. “Analisis Kebijakan Pegembangan Pariwisata (Intervensi Melalui Kebijakan Pariwisata Berkelanjutan di Bali)", Paper Seminar Nasional Pariwisata Berkelanjutan, Program S3 Pariwisata Universitas Udayana. 
Sunaryo, Bambang. 2013. Kebijakan Pembangunan Destinasi Pariwisata: Konsep dan Aplikasinya di Indonesia. Jakarta: Gava Media.

Suwantoro, Gamal. 1997. Perencanaan Produk Wisata. Yogyakarta: Diparda.

\section{Profil Penulis}

Ni Putu Rika Sukmadewi, S.Pd., M.Par. adalah alumnus Program Studi Magister Pariwisata Fakultas Pariwisata Universitas Udayana. Menyelesaikan pendidikan S1 pada Program Studi Pendidikan Bahasa Inggris di Fakultas Keguruan dan Ilmu Pendidikan Universitas Mataram pada tahun 2013, dan tahun 2015 melanjutkan Program Magister Pariwisata di Universitas Udayana dan tamat pada tahun 2018. Email: rika.sukmadewi@gmail.com

Prof. Dr. I Nyoman Darma Putra, M.Litt adalah guru besar Fakultas Ilmu Budaya Universitas Udayana. Darma menulis beberapa artikel di jurnal internasional dan beberapa buku biografi tokoh pariwisata Bali, serta menyunting beberapa buku, termasuk Pariwisata Berbasis Masyarakat Model Bali (2015) dan bersama Siobhan Campbell mengedit buku Recent Development in Bali Tourism Culture, Heritage, and Landscape in an Open Fotress (2015). Bersama Dian Sastri Pitanatri, Darma menulis buku Wisata Kuliner, Atribut Baru Destinasi Ubud (2016). Email: idarmaputra@yahoo.com

Dr. I Wayan Suardana, SST.Par., M.Par adalah dosen Prodi Magister Pariwisata, saat ini menjabat sebagai Wakil Dekan I Fakultas Pariwisata Universitas Udayana. Menyelesaikan pendidikan Diploma IV Pariwisata di Universitas Udayana pada tahun 2001. Sebelumnya memperoleh gelar magister pada Program Magister Kajian Pariwisata Konsentrasi Perencanaan Pariwisata Universitas Udayana pada tahun 2004. Pada tahun 2015 meraih gelar doktor pariwisata dari Universitas Udayana. Email: suar.dana@gmail.com 